\title{
The Image of the Arab East in the Travel Literature of the Silver Age
}

\author{
Eltsova Elena Nikolaevna ${ }^{1}$ \\ Associate Professor, Higher Institute of Languages, University of Carthage, \\ Tunis, Republic of Tunisia.
}

(date of receiving: June, 2019; date of acceptance: December, 2019)

\begin{abstract}
The Silver Age of Russian culture as a specific image of the world outlook marks rising tide of interest in East culture. That period was dominated by increasing the numerous travels to the Arab World and, as a result, ushered in creating a large body of travel literature. The important role in image-building of the Arab East culture played such countries of the African Continent as Tunisia, Algeria, Morocco, Egypt and Abyssinia. Demystifying the subject of weird Africa turned it to a "land for travelers" thus African issues heavily entered in Russian research and art space. If the interests of travelling scientists were focused on imperial policy of Russia, then the art world, full of mysticism and philosophy, discovered in the Arab World "wealth of knowledge" and returned to primitiveness and purity of archaic cultures. In this article, we represent Andrey Bely as one of the most famous Silver Age Symbolists. His journey to the East (Tunisia, Egypt) revealed not only oriental trend of Era, symbolic vision of eastern countries, but also reflected the writer's philosophical and creative thoughts, the start of new poetics.
\end{abstract}

Keywords: Silver Age, Arab East, Travel Literature, Andrey Bely, Tunisia, Egypt.

1. E-mail: elcova-elena@mail.ru 


\title{
Образ арабского Востока в путевой литературе Серебряного века
}

\section{Ельцова Елена Николаевна ${ }^{1}$}

Доцент, Высший институт языков Туниса, Университет Карфагена,

Тунис, Тунисская Республика.

(дата получения: июнь 2019 г.; дата принятия: декабрь 2019 г.)

\begin{abstract}
Аннотация
Серебряный век русской культуры как особый образ мировосприятия знаменует собой возрождение интереса к Востоку. В данный период значительно возрастает количество путешествий в страны арабского мира и создается большой пласт путевой литературы. Среди территорий, сыгравших значительную роль в формировании образа арабского Востока, важное место наряду с классическим Ближним и Средним Востоком начинают занимать страны африканского континента (Марокко, Алжир, Тунис, Египет, Абиссиния). С неведомой Африки снимается покров таинственности, она становится «землей для путешественников» и активно включается в русское исследовательское и художественное пространство. Если интерес ученых-путешественников во многом отражал имперскую политику России, то в художественном мире, полном мистицизма, философских и теософских исканий, арабский мир открывал глубокий пласт знаний и возвращал к первобытности, чистоте архаических культур. В рамках данной статьи рассмотрим путевую прозу яркого представителя литературы Серебряного века символиста Андрея Белого. Его путешествие на Восток (Тунис, Египет) раскрывает не только ориенталистские тенденции эпохи, символическое видение восточных стран, но и философские и творческие искания самого поэта, становление новой поэтики.
\end{abstract}

Ключевые слова: Серебряный Век, Арабский Восток, Путевая Литература, Андрей Белый, Тунис, Египет.

1. E-mail: elcova-elena@mail.ru 


\section{Введение}

Серебряный век как одно из значительных явлений философской и культурной жизни России на рубеже XIX-XX вв. знаменует собой возрождение интереса к Востоку, который вбирал в себя разноликие культуры: буддизм, индийский и тибетский мистицизм, китайское и японское искусство, египетскую, персидскую, абиссинскую, шумеро-аккадскую мифологию, ближневосточные ветхозаветные традиции. В художественной геософии данной эпохи Восток теряет четкие территориальные ориентиры и становится эстетическим понятием. По замечанию Е.В. Шахматовой, на рубеже веков «кризис европейской ментальности выявил острое противоречие между рационалистической картиной мира эпохи Нового времени и религией. Поворот к Востоку, его религиозно-философским системам, трактовавшим онтологические проблемы с позиций естественного равенства, стихийного гуманизма и необходимости совершенствования личности и мира, становился своеобразной формой протеста против прагматизма западной культуры» (Шахматова 2017. 5-6). В этот эпохальный исторический период происходит военная экспансия европейскими станами восточных территорий, противостояние Российской и Османской империей, покорение Кавказа и Средней Азии, Русско-японская война. Российская общественная мысль пытается определить свою самобытность в дихотомии «Запад - Восток». Образ арабского Востока проникает в этот период в Россию через популярную западную литературу, а также переводные материалы. Путевые очерки французских и английских путешественников печатаются в «Отечественных записках», «Современнике», «Русском вестнике», «Вестнике Европы», «Библиотеке для чтения» и т.д. Познанию реального Востока способствуют научные экспедиции Императорского Русского Географического Общества (1845), деятельность Русской Духовной Миссии в Иерусалиме (1847), бурный рост востоковедения, в том числе арабистики. Значительно возрастает количество путешествий 
(представители императорского двора, дипломаты, журналисты, художники, писатели и поэты, паломники) в страны арабского мира и создается большой пласт особого автобиографического дискурса - литература путешествий, ярко отразившей ориенталистские тенденции эпохи и в свою очередь повлиявшей на создание образа Востока в русском общественном и художественном сознании.

\section{Основная часть}

Среди территорий, сыгравших значительную роль в формировании нового для русского сознания образа арабского Востока в период Серебряного века, важное место на ряду с классическим Ближним и Средним Востоком, являющимся колыбелью древних культур и мировых религий, начинают занимать арабские страны африканского континента (Марокко, Алжир, Тунис, Египет, Абиссиния). С неведомой Африки снимается покров таинственности, она становится «землей для путешественников» и активно включается в русское исследовательское и художественное пространство. Путешественниками и учеными создается новая литературно-военноисторическая литература, содержащая богатый материал об отдаленных арабских странах (М.Ю. Венюков, А.В. Елисеев, А.А. Рафалович, В.Г. Галузеев, Л.Ф. Костенко, П.А. Чихачев, М.И. Ростовцев и др.). Если их интерес во многом соответствовал самой исторической обстановке и раскрывал имперскую политику России, то в художественном мире, полном мистицизма, философских и теософских исканий, новых образов и символов, арабский Восток открывал глубокий пласт знаний и возвращал к первобытности, чистоте архаических, земледельческих культур. Представители художественной элиты совершают поездки в различные североафриканские и ближневосточные страны: поэты и писатели А. Белый, К.Д. Бальмонт, Н.С. Гумилев, И.А. Бунин, М. Кузмин, Вяч. Иванов, В.А. 
Сологуб, поэт и философ В.С. Соловьев, художники К.С. Петров-Водкин, В.В. Кандинский, В.И. Якоби и др. Выразив свои историко-культурные, философские и собственно художественные впечатления в путевой прозе и поэзии, они создают богатейший материал литературы путешествий.

В рамках данной статьи обратимся к путевым заметкам яркого представителя литературы Серебряного века символиста Андрея Белого (псевдоним Бориса Николаевича Бугаева). Специальных работ, посвященных заметкам Белого-путешественника об арабском Востоке (Тунис, Египет), практически нет. Исключения составляют исследования Л.А. Сугай о теоретическом осмыслении Белым культурологии как самостоятельной науки и Е.А. Чач, рассмотревшей проявление ориентализма в общественном и художественном сознании Серебряного века. Пытаясь типологизировать путешествия «русских интеллектуалов» (А. Белого, К.Д. Бальмонта, И.А. Гриневской, Н.С. Гумилева, А.К. Булатовича, В.К. Арсеньева) по восточным странам, Е.А. Чач относит Белого к «типичным туристам»: «Андрей Белый путешествовал по Востоку с чисто туристической целью - «посмотреть», и стремился зафиксировать самый факт своего пребывания в тех или иных местах, часто романтизируя отдельные элементы «восточной» действительности» (Чач 2012. 166). Позволим себе не согласиться с данной точкой зрения, так как восточные впечатления Белого представляют не только геокультурный образ арабских стран, но и отражают становление культурнофилософской мысли России рассматриваемого периода, внутреннее движение переживаний самого поэта и формирование его поэтики, о чем неоднократно отмечал сам писатель-символист: «Питался я красками: я отдаваль ихъ, как мысли - высокому, чистому небу; я здьсь осозналь, что пути мои прежніе изжиты; что возвращенье на родину, мнь предстоящее, будетъ приходом 
впервые» ${ }^{1}$ (Белый 1922. 244-245); «...смена же путевых впечатлений соответствовала все время этапам наших переживаний; когда исчерпались впечатления, то кончились дни наших странствий...» (Из литературного наследства Андрея Белого 1937. 414).

В декабре 1910 г. Андрей Белый с женой молодой художницей Анной Алексеевной Тургеневой (в путевых заметках Ася) отправляются в Италию, где он предполагал остановиться и работать над новым романом. Однако первоначальный замысел не удался и они едут в Тунис, в Египет, потом в Палестину и возвращаются в Одессу 22 апреля 1911 г. Белый писал своему издателю Э.К. Метнеру «...В Палермо дорого, в Монреале сейчас наживем смертельную простуду, справились по Бедекеру; оказалось: в Тунисе дешевле, чем здесь; едем в Тунис и там проведем зиму» (Путешествие на Восток 1988. 144). Африканское путешествие стало своеобразным спасительным бегством из Москвы от семейных проблем и нерешенных вопросов с издательством, но оно значительно повлияло на философские и творческие искания, открыло путь «к новому духовному прозрению Белого и обусловила переход от софиологии Владимира Соловьева к антропософии Рудольфа Штейнера» (Шатин 2015. 390), стало путешествием от самого себя к новой философии и поэтике, позволило творчески осмыслить концепцию культуры. Отдельные очерки Белого, посвященные путешествию, были опубликованы еще в 1911 г. в газетах «Речь», «Утро России», «Современное слово». Главы «Египта» появились в 1912 г. в трех номерах журнала «Современник» (№ 5, 6, 7). Впервые первая часть книги была издана в 1921 и 1922 гг. под разными названиями: «Офейра» и «Путевые заметки». Толкование необычного названия путевых заметок «Офейра» можем обнаружить в ритмизованном эссе «Глоссолалия» (1917), где говоря о небесной Аэрии (Офейре или Зефиреи),

1. Цитаты приводятся с сохранением орфографии и пунктуации А. Белого. 
Белый подчеркивает, что этой желанной прародины человечества «нет на земле», «пропала она», что она образована из «невидимой обычному оку» субстанции и, наконец, что это, «облачный город, зажженный лучами», вожделенная «златая земля». На страницах «Путевых заметок» Белый возвращается к этому «сиянию, сказке лучей» и пишет, что Офейра находится в самом сердце Африки: «...африканские недра доселе таят неизвестности; береговая же Африка уже со времени Васко-де-Гама заселена европейцами; в недрах ее полагали когда-то «Офейру» (о ней гласят древние); солнце там жжет: пережженный есть «афф» - африканец. <..> к ней путь через Египет, через Нубию, через Судан к полноводным «нианзам» ...» (Белый 1994. 415).

«Африканский дневник» является продолжением и второй частью путевых заметок. Как пишет Белый в предисловии: «Цель этой книги дать несколько картинок из жизни и быта огромного африканского континента...» (Белый 1994. 330). Яркие восточные впечатления отражены и в письмах Белого, адресованные матери А.Д. Бугаевой, руководителю издательства «Мусогет» Э.К. Метнеру, литератору, музейному работнику А.С. Петровскому, издателю и библиофилу А.М. Кожебаткину. На протяжении всей своей жизни Белый будет неоднократно возвращаться к этой поездке, запечатлев символы своего путешествия в романе «Петербург» (1913-14) и мемуарной трилогии «Между двух революций» (1934). Б. Кузьмин, выделяя эту склонность Белого переосмысливать свои воспоминания, пишет: «..восприятие действительности было у Андрея Белого чрезвычайно противоречивым, и при его символическом мышлении - неопределенным и многозначным. Поэтому в разные моменты своего духовного развития он подчеркивает и выдвигает на первый план различные оттенки своих прошлых переживаний и размышлений» (Из литературного наследства Андрея Белого 1937. 410). В автобиографическом романе «Между двух революций» путевые впечатления будут пронизаны «идейными изворотами», желанием стать «идейным 
революционером» (Ходасевич 2008. 15) и поэтому будут включать новые откорректированные записи по отношению к буржуазной Европе и ее колониальной политике: «Открывалась мне здесь и сущность французского буржуа: перерождаться в колониях в паразита; я его наблюдал, как он мусорит местный быт отбросами своего быта, уместного, может, в Европе, но здесь отвратительного; колонизатор предстал мне в Африке, как гнилостная бактерия...» (Из литературного наследства Андрея Белого 1937. 424). Однако даже эти поздние вставки не могут стереть строй духовных переживаний писателя-символиста.

География восточных путешествий Белого связана с двумя североафриканскими странами: Тунисом и Египтом. История, культура, архитектура, быт, народы, населяющие эти страны, стали не только действующим лицом путевых заметок, но и способствовали созреванию автора как конденсатора духовной жизни своего времени. Путевые заметки и письма Белого, посвященные Тунису, пронизаны особым романтическим восхвалением Востока, богатством красок и линий в его описании. Н.В. Котрелев отмечает: ««Путевые заметки», кажется, триумф импрессионизма и лирики. Образ счастья светится со страниц. Скачут в причудливом ритме ассоциации, взятые из подручных путеводителей исторические и этнографические сведения, все заливают световые и цветовые впечатления, буйные краски. А за калейдоскопическим мельканием образов Белый открывает для себя новое видение мира» (Путешествие на Восток 1988. 146). Европейцу Белому в истории, архитектуре и быте жителей Туниса открывается особая философия жизни и особая культура, которая отличается от европейской. Эта новая культура кажется ему близкой, понятной и привлекательной: «Забываю, откуда пришелъ я; я - русскій; и я - европеецъ. Европа? Ее - забываю; ея - не хочу. Знаю въ Англіи, знаю, въ Германіи, я тосковаль бы по родинь; здьсь - не тоскую; здьсь точно родился; и - точно 
умру...» (Белый 1922. 244). В арабском Востоке он видит проявление настоящей культуры, образ цельного человеческого существования, сформировавшегося тысячелетиями на основе взаимодействия и взаимовлияния различных культур, историй, религий и народностей. Автор путевых заметок осознанно интерпретирует эту идею, пытаясь уловить глубочайшие противоречия между цивилизациями: Европой и Африкой, шире Западом и Востоком.

Белый представляет творчески осмысленную концепцию образа Востока, в которой значительную роль играет колористический и интонационный рисунок. В описании Туниса доминируют белый цвет: «Голубела туманная дымка; и таяла: а осньженіе, выдавалось рельефомъ, бьльло, бьльло, бьльло; и - Господи! Есть же предьль бьлизнь! Я предьль этоть знаю теперь: называю Тунисомъ его» (Белый 1922. 174). А метафора «белый Тунис» получает особое культурно-символическое наполнение в его художественном мире. В статье «Священные цвета» Белый, рассуждая об онтологической сущности наиболее значимых, выразительных, чистых, с точки зрения символической эстетики, цветов: белого, черного и красного, - отмечает, «белый цвет - символ воплощенной полноты бытия» (Белый 1911).

За внешней белизной Туниса скрывается его многоликость и пестрота красок: «...открываю окно на арабскую уличку; пестрыя пятна - гдь бьлый Тунисъ? Онъ - разстался на радугу красокъ; онъ издали бьлый; вблизи глянцевитый, фаянсовый, радужный» (Белый 1922. 178). Эта яркая световая картина преломляется в архитектуре, в декоративных элементах, в национальной одежде, в самой национальной палитре (берберы, туареги, арабы, испанцы...). Не случайно Белый отмечает: «Такъ и арабъ: какъ накинеть бурнусъ, - привидЬнье, бьльйшій туманъ; распахнется - оранжевый, синій, голубоватый и розовый онъ; и тунисская уличка: издали - бьлая; если приблизится - пестрая уличка» (Белый 1922. 178). 
Белизне арабского города контрастом выступает европейский: «Близокъ ужъ берегъ: и тутъ, - вблизи берега, видимъ: по бьлой, развернутой складкь бурнуса ползутъ, расширяяся, желтыя пятна, какъ ... грязь: европейскій кварталь ...» (Белый 1922. 175). В этой цветовой гамме путевых заметок противопоставлены не только два не соотносимых города: арабский и европейский, но и две культуры, два мировоззрения. Писатель четко разделяет эти два образа жизни (равно две культуры) и начинает размышлять о самом понятии «культура»: «Каждый день я бываю въ Тунисеь; въ «культурномъ Тунисеь»; и часто - въ арабскомъ; посльдній - культурнье, потому, что основа культуры - это умьніе жить; въ возсозданіи - знаніе; жизнь же - сознаніе: мудрое знаніе; знание, взятое въ смысль обычномъ научнаго знанія еще не знаніе - собственно, а половинное знаніе» (Белый 1922. 219). По Белому, «культура Тунисіи» и представляет то истинное законченное, цельное знание жизни, которое проявляется в архитектуре, в обычаях, в жестах и цвете. Французские нововведения забирают прелесть арабского города, и писатель не раз на страницах своих путевых заметок выражает свое разочарование культурной колонизацией: «Тунисъ - гдь Тунисъ? Не Тунисъ, а Парижъ»; «Ахъ, отчего загрязнили Тунисъ здьсь, у берега?» (Белый 1922.175).

В «Африканском дневнике» зазвучала шире лишь слегка затронутая в «Офейре» тема Африки. Белый пишет: «Пребывание в тихой арабской деревне, в Радесе (Белый с А. Тургеневой поселился в этом пригороде Туниса 15 января (н. ст.) 1911 г. и прожил там два месяца - Е.Е.) мне было огромнейшим откровением, расширяющим горизонты; отсюда я мысленно путешествовал в недра Африки, в глубь столетий, слагавших ее современную жизнь; эту жизнь мы уже чувствуем, тысячи нитей связывают нас с Африкой» (Белый 1994. 330). Ее олицетворением выступают тунисские арабы, «белые бурнусы» (плащ с капюшоном из белой шерстяной материи), как их нарицательно называет Белый. Африка противостоит Азии и монголам. 
«Африка так манит, так она в своих африканских чертах непохожа на Европу, так самобытна, целостна: подумайте, милый: целый громадный материк иной, не европейской земли; астрал, элементали - все, все здесь иное; иное клише «ви́дения〉. Не Европа Африка, но и не Азия; Азии вовсе нет, монгольства ни капли. Африка для меня неожиданный, многообещающий подарок моей поездки...» (Из письма к Э.К. Метнеру, Маскулла-Радес. 30 января / 12 февраля (н. ст.) 1911 г.) (Путешествие на Восток 1988. 156).

В «Африканском дневнике» зазвучало мистическое предчувствие будущего. Писатель-символист предсказывает события, происходящие в современном мире. Колониальная Африка, вобрав в себя «двадцать две» Франции, со временем покорит саму метрополию: «... я боюсь - будет час; кровь с огромною силой прильет к голове организма французской Европы, кровь черная: миллионами негров, мулатов вдруг хлынет в Париж, Марсель, Гавр, Лион, - Африка, так, жилы страны разорвутся, под мощным напором; и европейскую Францию быстро постигнет удар: почернеет ее голова; и в XXIII столетии будет Париж переполнен курчавыми толпами черных «чертей»: парижан!» (Белый 1922. 366).

Мотив грядущей вселенской катастрофы найдет последующее воплощение в описании Египта. Сам Белый эту поездку оценит как путешествие по «старинному континенту» души»: «...от Египта мои «Путевые заметки меняют свое направление; и становятся: путевыми заметками странника, ищущего новой жизни души; «география» и «этнография» заменяются в них «психологией», «метафизикой», неуместной в простых «путевых наблюдениях»» (Белый 1994. 452). Эта смена художественного взгляда отобразится в восприятии и последующем символическом изображении Египта. Разрыв между романтически завораживающим Тунисом и мистически отталкивающим Египтом Белый тонко выделит не только в архитектурной планировке, геометрии рисунка, звуковой ритмике, цветовой гамме и запахе, 
но и самой их метафизике: «Злой, неприятный, обидный Каир; это - первое впечатление наше; сравненье с Тунисом невольно. Миллионом разинутых ртов прогорланил Каир; и снежайше провеял немногими сотнями тысяч бурнусов Тунис. Белоснежен Тунис; черносер, серопылен Каир; чист Тунис; выгрязает Каир из-за бурого вороха сора; тунисские бельма пестрейше распались в фаянсовых глянцах гирлянд; темноватые стены Каира покрыли каймой серой грязи отчетливо черные прочертни; белый цветок, - наклонился Тунис лепестком куполов над лепечущим озером; тело Каира - зловонно дымеет песками; над злобовонною падалью (кошек, собак) - высоко зачертили круги прямокрылые коршуны; а над водой бирюзами легчайшей тунисской струи розовеют цветочки фламинговых крыльев; топорщатся стены Каира сплошным кривулем-завитком и причудливой лепкой орнамента, в складках которого - грязь; и квадраты, и кубы тунисских построек, снежнея, легчатся (Белый 1994. 391-392). Белое «снежение» Туниса сменяется отталкивающе мистическим «черным и серым». В теории цветовой символики писателя эти цвета имеют особую наполненность: черный трактуется как «символ небытия, хаоса», который определяет зло и нарушает полноту бытия. Серый как пограничный между черным и белым представляется воплощением «небытия в бытие, придающее последнему призрачность». Отсюда зло «заключается в относительной серединности, двусмысленности» (Белый 1911). В этой смене колористической наполненности (белый - черный, серый) и ее символики (жизнь - смерть, бытие - хаос) проявляется трагизм рубежа веков, символическое воплощение разрушающей силы нового времени.

Белый тонко подмечает и временной контраст двух географически единых, но культурно и антропологически разноликих стран: сцепление времен, характерное для тунисской культуры, в Египте сменяется разрывом настоящего и прошлого, современного и древнего. «Старый арабский Каир не волнует; а пятитысячелетний древний Египет, кометой врезаясь в сознание, в 
нем оживает как самая жгучая современность; и даже как предстоящее будущее. В чем сила, превращающая тысячелетнюю пыль в наше время? ...» (Из литературного наследства 1937. 432).

Тунисские «белые арабы», которыми так восхищался Белый в «милой Тунисии», противопоставлены «феллахам» («феллах не тунисец» (Белый 1994. 365). Их гортанные и монотонные голоса слились в путевых заметках не только в нарицательное обращение «хахи», но и стали символикой мертвенности: «все египтяне суть «хахи», или - вымыслы, призраки: так облеченное ныне в абассию ваше же тело - они; неуютно склониться над собственным... телом: и жуткостью дышит Египет: он - тело, которое сбросили, - труп; мы - над собственной тризной; отсюда - и муки, и казни; и - бегство; давно мы бежали отсюда; и - плен: полонил нас Каир!» (Белый 1994. 389).

Прогулки по арабскому Каиру с его душными улицами наполняют Белого мистическим ужасом «плена» и отсюда желанием убежать из него: «И странен, и страшен Каир» (Белый 1994. 390). Здесь столкнулись неприглядные картины действительности («город душный», «дрянные миазмы», «гнусный хамсин», «пекло», «навязчивость феллахов», «множество туристов», «ужасная дороговизна» жизни, острая нехватка денег) и древняя история, «рой летящих тысячелетий» Каира, «Голос Безмолвия», исходящий от Сфинкса (письмо А.С. Петровскому, Каир, 15 (2 н. ст.) марта, 1911 г.) (Путешествие на Восток 1988. 161). Здесь символы мучающих его вопросов обретают явные очертания. Пирамиды, мумии, Сфинкс получают в восприятии Белого не эстетическую оценку, как это было в предшествующем описании Туниса, а приводят к глубоким культурно-философским размышлениям и переживаниям. Белый пытается запечатлеть все движения самого «живого лица» - Сфинкса: «И более - получаса сидели под Сфинксом, одолевая круги выражений большого немого лица: идиотское выражение сменяло, летя, эфиопское; звериное, трупное, каменно-титаническое, царственное, лициферическое, духовное, 
ангельское, и - младенческочистое; так как бежит за волною волна, так бежали, сменяя друг друга, круги выражений; и в друг, закругляясь, в единство, круги выражений; сцеплялись в одно выражение: и прародимое время проснулось в круг выражений времен...» (Белый 1994. 430). Эти египетские впечатления, названные Белым «пирамидной болезнью», станут лейтмотивом всего его творчества: «Пишу эти несколько слов через восемь томительных лет; впечатления Египта со мною повсюду; Египет - во всем: и в туманно глаголющем Лондоне, как и в Берлине, прошел предо мною он; подстерегает меня он в Москве; выявляется гибельной мощью в стремленьях и вкусах, поет декадансом; понятен он всюду: он - всюду» (Белый 1994. 431). Мотив мертвенности Египта отражает философию Белого-символиста, который связывает гибель Европы, равно и современной ему культуры, с ее пресыщенностью и изжитостью как таковой.

\section{Заключение}

В эпоху рубежа веков путешествие становится особым методом познания Востока, его истории, культуры и духовности. Богатейший материал путевой литературы, созданный в данный период, несет информацию о странах, событиях, культурах и народах, а также дает концептуальное осмысление Востока. Рассмотренная в статье путевая проза символиста Андрея Белого является не только ярким художественным образцом символизма, но и пространством культуры, воссоздающим художественный метаобраз разноликого Востока. В путевой прозе Белого две североафриканские страны Тунис и Египет получают контрастное символическое воплощение. Тунисские впечатления пронизаны особым романтическим восхищением архитектурой, национальной одеждой, национальным колоритом, гармоничным слиянием исторического и настоящего, здесь у Белого рождается чувство родства России и Африки, себя и арабов. Яркий цветовой рисунок Туниса создан 
метафорическим и символическим звучанием, импрессионизмом красок и геометрических линий. Египет обостряет мистические переживания Белого, столь характерные для культуры Серебряного века. Его изображение противоречиво: здесь сплелись остатки древней цивилизации (Сфинкс, пирамиды, пустыня) и неприглядная поэту реальность. Но именно древний Египет становится символом иссохшей «мертвой» европейской культуры и лейтмотивом всего последующего творчества. Путешествие Андрея Белого на Восток стало не столько повестью о бегстве, столь характерной для литературы рубежа веков, а познанием себя через Восток, созданием новой культурно-философской мысли и поэтики.

\section{Литература}

1- Белый А. (1994). Африканский дневник / Публ. текста С. Воронина // Российский Архив: История Отечества в свидетельствах и документах XVIIIXX вв.: Альманах. - Москва: Изд-во «Наука». Т. 1. - С. 330-454.

2- Белый А. (1922). Путевые заметки: Сицилия и Тунис. - Москва, Берлин: Издво «Геликон». Т. 1.

3- Белый А. (1911). Свящченные цุвета // Арабески. Книга статей. - Москва, 1911. [Электронный pecypc] URL: http://az.lib.ru/b/belyj_a/text_07_1903_arabesky.shtml (дата обращения: 2.02.2018).

4- Из литературного наследства Андрея Белого (1937). Воспоминания. T. III, часть II (1910-1912). Предисловие Б. Кузьмина. Публикаиия К. Бугаевой. // Литературное наследство. Т. 27-28. - Москва: Изд-во «Журнально-газетное объединение». - С. 409-456.

5- Путешествие на Восток (1988). Письма Андрея Белого. Вступит. статья, публ. и коммент. Н.В. Котрелева // Восток - Запад. Исследования. Переводы. Публикации. - Москва: Изд-во «Наука». - С. 143-178.

6- Ходасевич Вл. (2008). Андрей Бельй // Андрей Белый. Петербург. Стихотворения. - Москва: Изд-во «Эксмо». - С. 7-16.

7- Чач Е.А. (2012). Русский интеллектуал на Востоке в эпоху Серебряного века: onыт типологизации // История и культура. Санкт-Петербургский гос. ун-т. № 9(9). - С. $163-203$.

8- Шатин Ю.В. (2015). Африка Андрея Белого и Николая Гумилева: лики травелога // Русский травелог XVIII-XX веков. Под. ред. Т.И. Печерской. Новосибирск. - С. 378-392. 
9- Шахматова Е.В (2017). Мифологема «Восток» в философско-эзотерическом контексте культуры Серебряного века. Дис. ... док. фил. н. -Москва.

\section{Bibliography}

1- Belyj A. (1994). Afrikanskij dnevnik / Publ. teksta S. Voronina // Rossijskij Arhiv: Istorija Otechestva v svidetel'stvah i dokumentah XVIII-XX vv.: Al'manah. Moskva: Izd-vo «Nauka». T. 1. - S. 330-454.

2- Belyj A. (1922). Putevye zametki: Sicilija i Tunis. - Moskva, Berlin: Izd-vo «Gelikon». T. 1.

3- Belyj A. (1911). Svjashhennye cveta // Arabeski. Kniga statej. - Moskva, 1911. [Jelektronnyj resurs] URL: http://az.lib.ru/b/belyj_a/text_07_1903_arabesky.shtml (data obrashhenija: 2.02.2018).

4- Iz literaturnogo nasledstva Andreja Belogo (1937). Vospominanija. T. III, chast' II (1910-1912). Predislovie B. Kuz'mina. Publikacija K. Bugaevoj. // Literaturnoe nasledstvo. T. 27-28. - Moskva: Izd-vo «Zhurnal'no-gazetnoe ob\#edinenie». - C. 409-456.

5- Puteshestvie na Vostok (1988). Pis'ma Andreja Belogo. Vstupit. ctat'ja, publ. i komment. N.V. Kotreleva // Vostok - Zapad. Issledovanija. Perevody. Publikacii. Moskva: Izd-vo «Nauka». - S. 143-178.

6- Hodasevich Vl. (2008). Andrej Belyj // Andrej Belyj. Peterburg. Stihotvorenija. Moskva: Izd-vo «Jeksmo». - S. 7-16.

7- Chach E.A. (2012). Russkij intellektual na Vostoke v jepohu Serebrjanogo veka: opyt tipologizacii // Istorija i kul'tura. Sankt-Peterburgskij gos. un-t. № 9(9). - S. 163-203.

8- Shatin Ju.V. (2015). Afrika Andreja Belogo i Nikolaja Gumileva: liki traveloga // Russkij travelog XVIII-XX vekov. Pod. red. T.I. Pecherskoj. Novosibirsk. - S. 378392.

9- Shahmatova E.V (2017). Mifologema «Vostok» v filosofsko-jezotericheskom kontekste kul'tury Serebrjanogo veka. Dis. ... dok. fil. n. -Moskva.

\section{HOW TO CITE THIS ARTICLE}

Ельцова Е. Н. (2020). The Image of the Arab East in the Travel Literature of the Silver Age. Issledovatel'skiy Zhurnal Russkogo Yazyka I Literatury, 8(1), 67-82.

DOI: $10.29252 /$ iarll.15.67

URL: http://www.journaliarll.ir/index.php/iarll/article/view/109 


\title{
تصوير شرق عربى در سفرنامهاى سده نقرهاى
}

\author{
يلنا نيكالايونا يلتسووا'

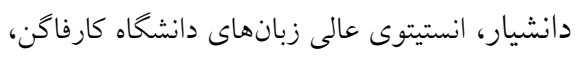 \\ تونس، جمهورى تونس.

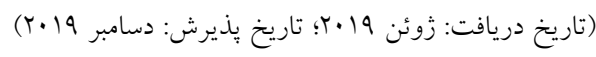

سدة نقرهاى در فرهنگ روسيه در شكل گيرى جهانبينى خاصى كه توجه ويزهاى به تمــدن

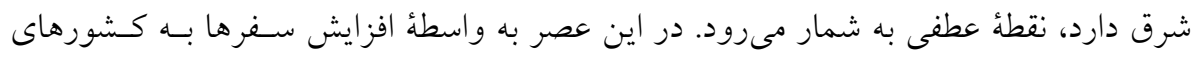

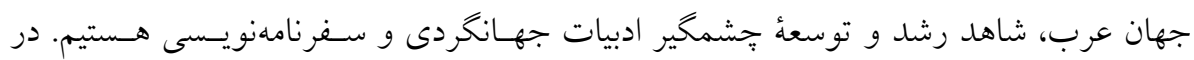

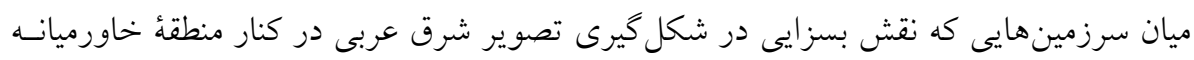

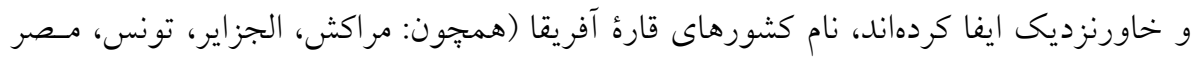

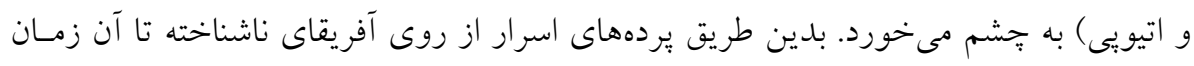

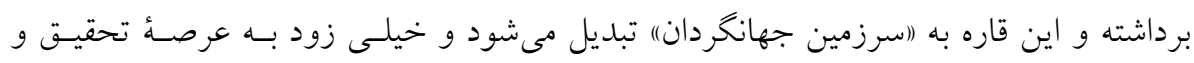

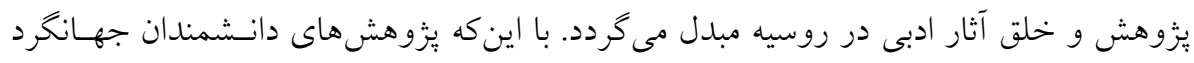

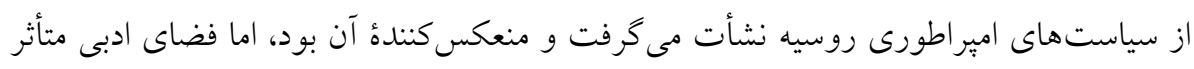

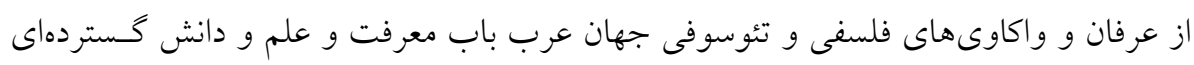

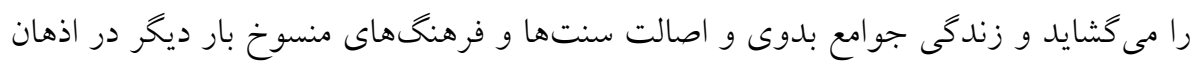

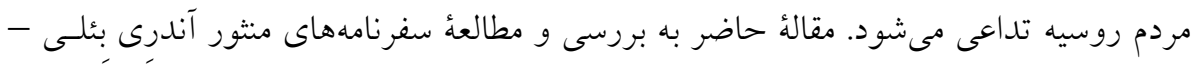

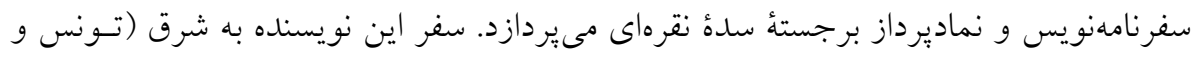

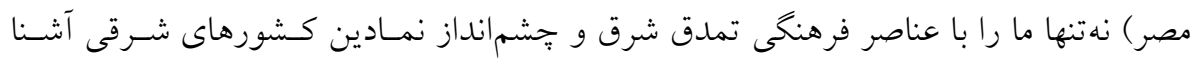

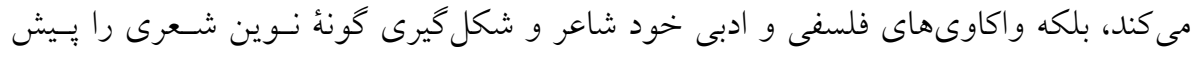
روى جشم ما قرار مى مهد.

وازگًان كليدى: سدة نقرهاى، شرق عربى، سفرنامهنويسى، آندرى بئلى، تونس، مصر. 